\title{
Research on the Innovation Strategy of Knowledge Management System in Guangzhou College of Technology and Business
}

\author{
Xie Baosheng \\ Department of Business Administration \\ Guangzhou College of Technology and Business, 510850, \\ Guangzhou, Guangdong, China
}

\author{
Deng Tongbo \\ Department of Business Administration \\ Guangzhou College of Technology and Business, 510850, \\ Guangzhou, Guangdong, China
}

\begin{abstract}
Under the background of knowledge economy, the implementation of knowledge management in Guangzhou College of Technology and Business is the vital method to train and enhance its core competitiveness. Based on this aim, this paper put forward four strategies for the knowledge management system innovation in the college from the aspect of transforming teachers' ideas, creating knowledge sharing and innovative environment, constructing perfect knowledge management system and promotes knowledge management development to enhance core competitiveness through stating the system construction and the value of strengthening the core competitiveness.
\end{abstract}

Keywords-Guangzhou College of Technology and Business; knowledge management; core competitiveness; system innovation; strategy

\section{INTRODUCTION}

With rapid development of knowledge economy, the social environment of Guangzhou College of Technology and Business has changed dramatically, which poses an unprecedented challenge to the development of this college. College development aims at training talents meeting the demands of social development to enhance its core competitiveness in the market. Guangzhou College of Technology and Business is a typical knowledge-intensive institution. And the emphasis of enhancing its core competitiveness is to regard knowledge management as the basic part of its management activity and effectively construct sound knowledge management system.

\section{CONNOTATION AND GENERAL SYSTEM OF KNOWLEDGE} MANAGEMENT IN GUANGZHOU COLLEge OF TECHNOLOGY AND BUSINESS

\section{A. Connotation of knowledge management}

The concept of knowledge management started in the 1990s and has not yet formed a standard definition. At present, there are three kinds of knowledge management scholars at home and abroad: technical, behavioral and comprehensive. Technical scholars focus on information technology and they think that knowledge management is the management with information. And behavioral scholars believe that knowledge

Education science planning issue in Guangdong province: "Research on the innovation of knowledge management systemin Guangzhou College of Technology and Business” (Grant No. 2017GXJK207) management is the management with people, and they attach great importance to the study of organization and learning process. While comprehensive scholars believe that knowledge management should connect information and people besides managing them [1]. In summary, we can obtain the basic connotation of knowledge management, namely, knowledge management refers to organize internal members to take the advantage of modern computer, network and communication technology to develop, manage and use knowledge around the organization in a certain environment. It can promote the process of knowledge acquisition, dissemination, sharing, using and innovation at the same time of reforming organization structure and realizing knowledge increasing to promote the core competitiveness of organization [2].

\section{B. Overview of knowledge management system in Guangzhou College of Technology and Business}

Guangzhou College of Technology and Business is also introducing the idea of knowledge management into its daily management activities through the in-depth study of the theories and methods of knowledge management and its successful application in enterprises. Its knowledge management system mainly adopts modern computer, communication and network technology to obtain all-form knowledge related with education and scientific research. Arrange, store, use, share and create this knowledge to enhance school-running quality, theories of serving social comprehensive abilities and technological system framework.

As a highly knowledge-intensive institution, Guangzhou College of Technology and Business specifically majors in knowledge dissemination, creation, application and integration. Various explicit knowledge is distributed in the college, such as management system, teaching documents and scientific research achievements; and there is also creative tacit knowledge, such as management experience, academic environment, teaching methods, scientific research skills, collaboration forms and communication means. Its knowledge management is mainly to effectively promote the continuous transformation between explicit knowledge and tacit knowledge, especially the rationalization of tacit knowledge. Realize knowledge sharing and continuous innovation and improve the overall knowledge application level of faculty and 
staff to further strengthen the core competitiveness of the college.

\section{KNOWLEDGE MANAGEMENT ENHANCES THE VALUE REPRESENTATION OF CORE COMPETITIVENESS IN GUANGZHOU College of TeChNOLOgy and Business}

The concept of core competitiveness comes from enterprises, while colleges, as special knowledge-intensive institutions, should also improve their core competitiveness. The foundation of its core competitiveness is the distinct knowledge resource. And the implementation of knowledge management means creating and using knowledge to obtain organization performance. The introduction of knowledge management is conductive to promote its core competitiveness [3].

The tacit knowledge inside Guangzhou College of Technology and Business mainly refers to the experience, skills and cognition of the development rules of things that are extracted from teaching and scientific research work by the faculty. These are difficult to be imitated by competitors. Knowledge management is mainly to promote the constant transformation between explicit knowledge and tacit knowledge and realize the continuous innovation of knowledge to meet the needs of society and its own development and gain the competitive advantage of knowledge [4]. The knowledge management of Guangzhou College of Technology and Business should involve everyone in the college. Only by everyone actively participating in the knowledge management can they truly narrow the internal knowledge gap, expand the competitive advantages and strengthen the core competitiveness.

\section{INNOVATION STRATEGY OF KNOWLEDGE MANAGEMENT System IN GUANGZHOU COLlege of TECHNOLOgY AND BUSINESS}

\section{A. Transform the concept of teachers}

The construction of knowledge management system in Guangzhou College of Technology and Business is a systematic project. The concept with implementing knowledge management of all teachers, especially college leaders, has been the key factor for the success of carrying out knowledge management. Only when they understand that the construction of knowledge management system is helpful to promote the core competitiveness of colleges and perfect knowledge management system can promote tacit knowledge sharing and innovative management system, can they do well in the reform of college management from the perspective of sustainable development and knowledge management and realize the target of college knowledge management. In the process of implementing knowledge management, college leaders are supposed to deeply understand that knowledge management is a progressive process of continuous exploration, innovation, summary and implementation. All faculty and staff, at the same time of fully understanding that knowledge is composed of explicit and implicit knowledge, should attach importance to knowledge sharing, realize the interaction and communication among individuals through knowledge management platform and enhance their knowledge application ability to further improve the core competitiveness of the college.

\section{B. Create the environment of knowledge sharing and innovation}

Knowledge management cannot be separated from the knowledge management system platform built by modern computer, network and communication technology [5]. At present, Guangzhou College of Technology and Business has established a modern office system, and the computer network touches all functional departments, classrooms and laboratories. Technology is mainly to expand the access to knowledge, accelerate the speed of knowledge dissemination, and provide technical guarantee for knowledge mining and sharing in knowledge management. What's more, the college should establish a knowledge-sharing and innovation-oriented incentive mechanism and actively create a relaxed working and learning environment to enable its faculty and staff to accept the concept of knowledge sharing and build a competitive relation with coordinated development as well as the system of coexistent interests. Meanwhile, teachers are supposed to understand that knowledge sharing is the foundation for implementing knowledge management and knowledge innovation is the driving force to realize the sustainable development that needs colleges do well in knowledge innovation. In the era of knowledge economy, the depth and direction of college knowledge innovation will determine its future and destiny. The formation of knowledge sharing and innovative culture will increase the development advantages of Guangzhou College of Technology and Business to further enhance its core competitiveness.

\section{Construct perfect knowledge management system}

A good knowledge management atmosphere must be based on the organization culture of knowledge sharing, which should be supported by management system and knowledge management system [6]. In order to meet the needs of staff and students to exchange experiences, discuss problems, seek knowledge and online training and learning, they should construct the framework of computer technology, network technology and communication technology, create technology platform of knowledge sharing and innovation and form the organic network system including collection, storage, sharing, application, innovation and evaluation of knowledge. The relationship structure of knowledge management system in Guangzhou College of Technology and Business is shown as follows:

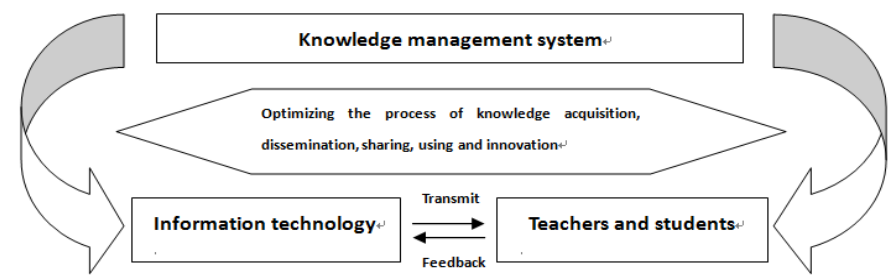

Fig. 1. Relationship structure of knowledge management system in Guangzhou College of Technology and Business 
Knowledge management is significant in the development of Guangzhou College of Technology and Business. And the following six conditions should be met before the implementation:

1. Establishment of "Scientific Development Outlook" is the premise of knowledge management. The mainstream of the knowledge economy era is to develop innovative thinking mode. And the school running idea of this college must regard the "Scientific Development Outlook" as its guiding ideology, which means moving from the college to society and acquire the knowledge, concept and technology conducive to management innovation.

2. The emphasis of faculty, especially college leaders, is the guarantee of knowledge management. With the constant development of knowledge economy, the role of college leaders and teachers has changed dramatically. College leaders are mainly to establish a common vision, create a good learning and academic environment, and guide the team to carry out creative work, advocate and establish learning groups.

3. Information technology is the basic of carrying out the work of knowledge management. The knowledge management system platform established by Guangzhou College of Technology and Business via information technology has the function of knowledge base management and the advantage of collaborative work, which is a necessary tool to implement knowledge management.

4. Establishing the incentive mechanism is the booster of carrying out knowledge management. In order to avoid risks and ensure return of investment, knowledge owners will protect their own knowledge. Such method conflicts with the concept of creating benefits by knowledge sharing [7]. Therefore, this college must establish an effective incentive mechanism for knowledge management to make faculty actively innovate, share and apply knowledge

5. The integration of knowledge resources is vital for knowledge management. The core of knowledge management is the development, dissemination, management, sharing and utilization of knowledge. The construction of knowledge resource base is the focus of carrying out knowledge management. So, teachers can regard the construction of knowledge resource base as the process of knowledge development, accumulation, update and dissemination on the basis of their own reality, teaching characteristics and knowledge management thought. The process of knowledge resource integration is shown as follows:

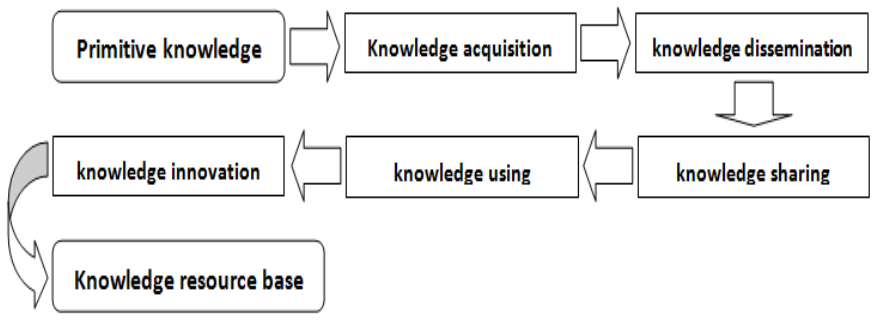

Fig. 2. Flow chart of knowledge resources integration
6. Optimizing learning support service is the main measure of knowledge management. The objective of carrying out knowledge management in Guangzhou College of Technology and Business is to improve education means and quality. It should be prepared from the following three aspects: first, improve the service of resource supply and realize the sharing of teaching resources; Second, offer online learning services to give full play to the role of the Internet so that teachers and students can study anytime and anywhere; Third, instruct teachers and students to work out a study plan fitting themselves.

\section{Promote the development of knowledge management to strengthen core competitiveness}

The management of Guangzhou College of Technology and Business mainly involves cultural management, functional management and business management. And cultural management is the basic of implementing knowledge management, aiming at the construction of knowledge management culture to make knowledge management rely on campus culture with the feature of knowledge sharing and innovation. Functional management is the guarantee to carry out knowledge management, and the focus is on the establishment of a "people-oriented" management system [8]. Business management comprises four aspects: teaching, scientific research, students and social service management. As the subject of knowledge management, it is also significant to strengthen the core competitiveness of college.

Only by immersing cultural management, functional management and business management into the knowledge management system platform can Guangzhou College of Technology and Business effectively carry out knowledge management. The activities of knowledge acquisition, storage, sharing and innovation can be used to promote these four functions to train excellent talents and obtain abundant research results and create more economic and social benefits and enhance its core competitiveness. The internal relationship of the core competitiveness in Guangzhou College of Technology and Business is shown as follows:

Core competitiveness in Guangzhou College of Technology and Business

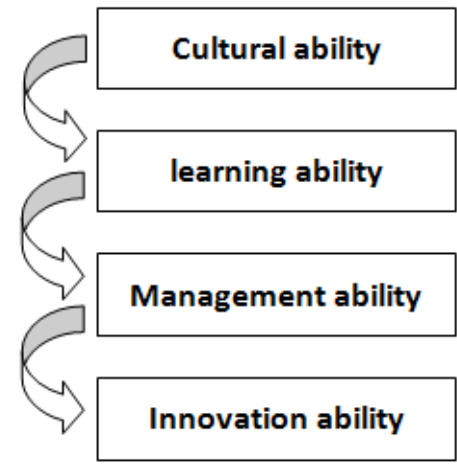

Competitive advantages in Guangzhou College of Technology and Business

Fig. 3. The internal relationship diagram of the core competitiveness in Guangzhou College of Technology and Business 


\section{Conclusion}

As a new-type management concept and method, knowledge management of Guangzhou College of Technology and Business regards knowledge as the resource, carrier and object of management. It effectively integrates, innovates and uses knowledge to promote the accumulation of knowledge resource and realize the value of knowledge so as to enhance the contribution degree of knowledge in social development. Besides, science and effectiveness of knowledge management work is the key to improve core competitiveness of this college. So, the innovation of knowledge management system is of great strategic significance.

\section{REFERENCES}

[1] Cheng Jia. Study hard: improvement guide of personal knowledge management[M]. Beijing: Citic Press,2017.

[2] Shen Enping. Knowledge management and organization learning intrinsic support to promote enterprises' cooperative and innovative abilities[M]. Hangzhou: Zhejiang University Press,2017.

[3] David Bulkush(author), Zhao Jingou(translator). New management revolution: How does knowledge economy reshape the organization and management[M]. Beijing: Citic Press,2017.

[4] Peng Chuanyu. Research on the psychological contract of knowledge workers under the background of knowledge economy[M]. Chengdu: Sichuan university press, 2017.

[5] Wang Lianjuan, Zhang Yuexian and Zhang Yi. Knowledge Management[M]. Beijing: Posts and Telecom Press,2016.

[6] Cheng Wen. Knowledge management for innovation-oriented enterprises[M]. Beijing: China Machine Press,2015.

[7] Wang Yongjie, Zhang Lue and Leng Wei. Knowledge economy and innovation[M]. Chengdu: Southwest Jiaotong University Press,2014.

[8] Ge Xinhng ang Huang Sihan. Follow with us to do knowledge management[M]. Beijing: Beijing University Press,2014. 